\title{
The Effect of Temperament on Emotion Regulation among Chinese Adolescents: the Role of Teacher Emotional Empathy
}

\author{
Xiaomei Shen \\ Students Affairs Department, Yancheng Institute of Technology, Yancheng City, China \\ Wenhai Zhang (Corresponding author) \\ Students Affairs Department, Yancheng Institute of Technology \\ 9 Xiwang Dadao, Yancheng City 224051, China \\ Tel: 86-515-88298755Ｅ-mail: zwh2007106@126.com
}

Received: December 23, 2011

doi:10.5539/ies.v5n3p113
Accepted: December 29, 2011 Online Published: April 28, 2012

URL: http://dx.doi.org/10.5539/ies.v5n3p113

This study is supported by Jiangsu university philosophy and social science research fund projects (2010SJB880117) and by Chinese Ministry of Education, Humanities and Social Sciences Planning Fund (11YJA190024).

\begin{abstract}
Hierarchical linear modeling techniques were used to explored individual and contextual factors of emotion regulation in a sample of 2074 adolescents from grade 7 through grade 12 and 54 head teachers in China mainland. Emotion Regulation Questionnaire (ERQ) and Early Adolescent Temperament Questionnaire-Revised (EATQ-R) were administered among students and Multi-Dimensional Emotional Empathy Scale (MDEES) among head teachers. Results showed that at the student level, Effortful Control and Affiliativeness were positively related to adolescents' reappraisal whereas Surgency was inversely correlated with reappraisal after gender, grade level and parent's education were controlled. And Negative Affect (NA) positively predicted suppression. At the teacher level, teachers' Emotional Contagion promoted the impact of adolescent Surgency on reappraisal after teaching age was controlled. In addition, Responsive Crying, Emotional Attention and Feeling for Others enhanced the influence of NA upon Suppression among teachers. However, Positive Sharing weakened the negative association between NA and Suppression. These findings expand the understanding of the role of teacher empathy in adolescents' emotional development, and have important implications for classroom management and teacher empathy training.
\end{abstract}

Keywords: Temperament, Emotion regulation, Hierarchical linear models, Empathy, Teacher, Adolescent

\section{Introduction}

As a key ability for adolescents to live through the immensely biological, psychological and social changes, emotion regulation (ER) has received increasing research attention in past years (Campos et al., 2004). These researches mostly focused on two aspects of individual and environmental factors. There-into, one of the key problems in these ER researches which are not still solved well now is how contextual variables exert an influence on ER through within-individual variables (Gross \& Thompson, 2007). Statistically, traditional regression analysis places individual and contextual variables on the same level, and can not exactly differentiate the modulation of contextual variables from the influence of individual variables on ER, which forms its main fault in analyzing individual and contextual influence at the same time. In contrast, the advantage of hierarchical linear model (HLM) is to place individual and contextual variables at different levels and simultaneously deal with them. Now we have the chance to study how contextual variables modulate the role of individual variables in the process of ER by HLM as follows.

ER generally refers to the ability to understand emotions and modulate emotional experience and expression (Gross, 1998), and is comprised of a multitude of physiological, cognitive, and behavioral overlapping processes (Zeman et al., 2006). The maturation of these ER capacities is considered to be central to the individual's growing abilities to handle stress, develop coping skills, and modulate attentive and learning processes. Most researches focused on cognitive reappraisal (antecedent-focused) strategy and expressive suppression (response-focused) strategy (Gross \& Thompson, 2007). Reappraisal is a cognitive-linguistic strategy that alters the trajectory of emotional responses by 
reformulating the meaning of a situation and decreases negative emotional experience. Conversely, Suppressors also report lower levels of self-esteem and life satisfaction, and more depressive symptoms.

On the one hand, the development of ER is partly shaped by temperamental predispositions (Gross \& John, 2003). Particularly, Rothbart and Bates (2006) built their temperament theory including effortful control (EC) which was believed to regulate dispositional reactivity and involve the effortful or willful control of attention and behavior. Moreover, early individual differences in affective temperament, particularly those reflecting emotional negativity and reactivity, appeared to influence the development of ER capacities (Blair et al., 2004). For instance, Cumberland et al. (2003) have noted that emotion and its regulation lie at the core of the conceptualization and measurement of early childhood temperament. Thus, we expect that there will be the direct association between the temperament dimension of EC and ER strategies of reappraisal and suppression, which is still unsolved to date (see Yap et al., 2007 for a review).

On the other hand, the environmental characteristics also influence ER processes. An abundance of researches indicated that the family care-giving environment plays a crucial role in children's development of ER skills (McWayne et al., 2008). In school, the results of numerous correlative and longitudinal investigations have been conducted in different geographical locations with students in different developmental stages, which suggested that teacher-student relationship patterns are associated with social, emotional, and school related to adjustment and functioning (Murray \& Malmgren, 2005). Recently, people have started to become interested in classroom emotional aspects such as teacher empathy.

Like general empathy conceived of a multi-dimensional construct with distinctions among its various attributes (e.g., personal distress, empathic concern, and perspective-taking; Davis, 1983; Thornton \& Thornton, 1995), Tettegah \& Anderson (2007) described teacher empathy as the ability to express concern and take the perspective of a student. Although we recognize that teacher empathy involves cognitive and affective domains, we are especially interested in its emotional components using MDEES to measure teacher's empathic dispositions, whose item contents are different from the cognitive measurement of empathy as ability (Caruso \& Mayer, 1998).

Emotional empathy is especially important for teachers to help students and facilitate students' ER development. For example, qualitative research indicated that empathic teachers are revealed as highly moral individuals (Cooper, 2004). They attach themselves mentally and emotionally to their students, and students generate similar responses in return. Because empathy has been regarded as an important disposition for teachers to possess in order to promote positive interactions among students (Good \& Brophy, 2000), we expect that teacher emotional empathy will give an impact to the association between temperament and ER. That is, teacher emotional empathy will modulate the effect of temperament on reappraisal and suppression. This paper commits itself to this issue to provide more information about the role of teacher emotional empathy in adolescent ER.

In summary, adolescent ER comes under the influence of both temperament differences and classroom contextual factors. This article will identify differences in ER processes of reappraise and suppress as core individual-level characteristics, which are believed to be particularly salient to classroom influence or head teacher. Inquiry which aims at disentangling the impact of teacher emotional empathy on students is by its very nature multilevel, as teachers are matched with students according to classroom grouping (e.g., students are nested within teachers). The advent of HLM has made it more possible to accurately estimate teachers' effects when nesting occurs. Using two-level HLM, we can deal with level-1 (student-level) and level-2 (teacher-level) simultaneously. Especially, this study is to explore the role of teacher emotional empathy in adolescents' ER by HLM.

\section{Methods}

\subsection{Participants}

The sample was conveniently selected from two junior high schools and two senior high schools, which belonged to a single urban district in Yancheng City of China, including 9 classes per grade and one head teacher per class from grade 7 through grade 12 . The initial average class size was 55 , but only about 45 students signed the consent form and agreed to take part in the questionnaire investigation. After excluding invalid questionnaires, the minimum size of class was 32, and the maximum was 42 . The final sample consisted of 2074 students ranging from 13 to 19 years (51.64\% male, $48.36 \%$ female; see Table 1 in detail) and 54 head teachers whose teaching experienced ranged from 3 to 23 years ( $18.5 \% 1-5$ years, $22.2 \%$ 6-10 years and $11-15$ years and $16-20$ years respectively, $14.8 \%$ over 20 years; $46.3 \%$ male, $53.7 \%$ female). As for the educational level of the students' fathers, $1 \%$ had a master degree or above, $7.2 \%$ had a college degree, $39.2 \%$ graduated from senior high school, $52.7 \%$ graduated from junior high school or below. As for their mothers' educational level, $1.8 \%$ had a master degree or above, $3.6 \%$ had a college degree, $27.5 \%$ graduated from senior high school, $67.1 \%$ graduated from junior high school or below. All the students and teachers were the Han nationality. 


\subsection{Measures}

The Chinese versions of the following measurement tools were translated from their English versions by the second author, and their original forms and structures were retained to keep in tune with the related literature.

\subsubsection{Emotion Regulation}

Emotional Regulation Questionnaire (ERQ; Gross \& John, 2003) consisted of 10 items touching upon the intended emotion regulatory strategy, including 6 items for Reappraisal (e.g., "I control my emotions by changing the way I think about the situation I'm in") and 4 items for Suppression (e.g., "I control my emotions by not expressing them"), which were rated on a scale from 1 (strongly disagree) to 7 (strongly agree). Alpha reliabilities averaged .79 for Reappraisal and .73 for Suppression when considering four different American samples. Results from exploratory factor analyses showed that two factors accounted for more than $50 \%$ of the variance in each sample of four different Americans. Confirmatory factor analyses showed that independence model (two factors correlating zero) was the best fit in contrast to other models. Test-retest reliability across 3 months was .69 for both scales. The two scales also showed good convergent and discriminate validity (see Gross \& John, 2003 in detail).

\subsubsection{Temperament}

The 65-item short form of the Early Adolescent Temperament Questionnaire-Revised (EATQ-R; Ellis \& Rothbart, 2001) was a revision of a measure developed by Capaldi \& Rothbart (1992). The revised questionnaire assessed 10 aspects of temperament related to self-regulation in adolescents, including activation control, affiliation, attention, fear, frustration, high-intensity pleasure, inhibitory control, perceptual sensitivity, pleasure sensitivity, and shyness, which comprised four subscales: EC, Surgency, Negative Affect (NA), Affiliativeness. Items were rated on a 5-point scale ranging from 1 "almost always untrue of you" to 5 "almost always true of you". Alpha reliabilities ranged from .79 to .84 for the 10 temperament scales. The correlation coefficients between the subscales and the total scale were more than .90 . Convergence with parent report was high for most scales, but poor for shyness and inhibitory control for males. In summary, EATQ was a reliable tool for the measurement of temperament in adolescents (Ellis \& Rothbart, 2001).

\subsubsection{Emotional Empathy}

Multi-Dimensional Emotional Empathy Scale (MDEES; Caruso \& Mayer, 1998) consisted of 30 items, and assessed 6 aspects of emotional empathy, including Empathic Suffering, Positive Sharing, Responsive Crying, Emotional Attention, Feeling for Others, and Emotional Contagion. A five-point response scale was used, where 1 was "Strongly Disagree" and 5 was "Strongly Agree". MDEES had internal consistency reliability as measured by coefficient alpha of .86, with individual subscale score alpha reliabilities ranging from .71 (for a 2-item subscale) to .84 (for an 8 -item subscale). The MDEES showed good structure validity in the factor analysis and significant relationships to a number of behavioral criteria (see Caruso \& Mayer, 1998 in detail).

\subsection{Procedure}

In China, most school activities, including academic instruction, are conducted within a class as the organizing unit (Eisenberg et al., 2007). Head teachers exert more influences on students than other teachers, because they see their students every day, either individually or in groups, and maintain close contact with the parents, many of whom know the school only through the head teachers. So this research invited head teachers to help administer questionnaire measurements and take part in this study.

Under consent of the four principals, the first author firstly visited four middle schools during two weeks in the spring semester and trained head teachers how to administer measurements. Then, every head teacher distributed 45 questionnaires to students in term of class unit where students were administered the self-report EATQ-R, ERQ and demographic questionnaire during normal study period while other nonparticipating students did their homework. In the meantime the participating students were asked to bring back informed consent forms from their parents in the next morning. All parents signed informed consent forms and agreed that their children took part in the research. After distributing questionnaires, 54 head teachers also filled in the self-report MDEES and demographic questionnaire. They were provided with the same explanation given to the students about confidentiality and were compensated 50 Yuan RMB for their work. In an anonymous way teachers and students only filled the class number in their questionnaire, but their names did not arise on the questionnaires. The whole measurement process lasted for about twenty minutes.

Several demographic measures were included as control variables. Gender was coded as a dummy variable, where 0 $=$ male and $1=$ female with male as the reference category; Grade-level was represented by five dummy variables, with grade 7 serving as the comparison group; similarly, Dummy variables were also created for teaching experience with over 20 years as the comparison group and parent education with over master degree as the reference category. 
In subsequent HLM analyses, these dummy-level variables except grade level were grand-mean centered (as were all other predictor variables). All continuous variables were transformed into $z$ scores across classes so that results could be reported as standardized deviation units.

The software program for Windows HLM 6.06 (WHLM; Raudenbush \& Bryk, 2002) was selected for the present study due to its ease of use. HLM analyses proceeded in three steps. First, between-classrooms variance in ER was examined using unconditional model. Second, student-level predictors of ER were examined on the level 1. Third, teacher-level variables were added to the model to examine level 2 predictors of ER while controlling for individual differences. Pair-wise deletion of missing values was utilized in these analyses at level 1 . There were no missing values at level 2.

\section{Results}

Descriptive statistics and correlations were presented for student-level variables in Table 2. Reappraisal was correlated positively with EC $(r=.14, p<.01)$, NA $(r=.05, p<.05)$, and Affiliativeness $(r=.19, p<.01)$, inversely with Surgency $(r=-.12, p<.01)$. Suppression was positively associated with NA $(r=.10, p<.01)$ and Affiliativeness $(r=.05$, $p<.05)$.

\subsection{Unconditional Model}

As a first step, reappraisal and suppression were separately entered into the HLM analysis as a dependent variable with no predictors in the models. The unconditional models provided reliability and the amount of between-classrooms variance of each construct (see Table 3). Although variance components of reappraisal and suppression were small, very significant Chi-square values indicated that ER lay in important between-classrooms variation.

Level 1

Level 2

$$
\text { reappraisal }_{i j} / \text { suppression }_{i j}=\beta_{0 j}+\gamma_{i j}
$$

$$
\beta_{0 j}=r_{00}+u_{0 j}
$$

Insert Table 3 about here.

\subsection{Student-level}

Two student-level models were separately run with characteristics of students such as gender, grade level, father education and maternal education, and self-reported temperament as level-1 predictors of reappraisal and suppression. The student-level models were expressed by the following equations:

Level 1

$$
\begin{aligned}
& \text { reappraisal }_{i j} / \text { suppression }_{i j}=\beta_{0 j}+\beta_{1 j}\left(\text { gender }_{i j}\right)+\beta_{2 j}\left(\operatorname{grade}_{i j}\right)+\beta_{3 j}\left(\operatorname{grade}_{i j}\right)+ \\
& \beta_{4 j}\left(\operatorname{grade}_{i j}\right)+\beta_{5 j}\left(\operatorname{grade}_{1 j}\right)+\beta_{6 j}\left(\operatorname{grade}_{1 j}\right)+\beta_{7 j}\left(\text { fcollege }_{i j}\right)+ \\
& \beta_{8 j}\left(\text { fsenior }_{i j}\right)+\beta_{9 j}\left(\text { fjunior and below }_{i j}\right)+\beta_{10 j}\left(\text { mcollege }_{i j}\right)+\beta_{11 j}\left(\text { msenior }_{i j}\right)+ \\
& \beta_{12 j}\left(\text { mjunior and below } w_{i j}\right)+\beta_{13 j}\left(\text { effortful control }_{i j}\right)+\beta_{14 j}\left(\text { sugency }_{i j}\right)+ \\
& \beta_{15 j}\left(\text { negative affect }_{i j}\right)+\beta_{16 j}\left(\text { affiliativeness }_{i j}\right)+r_{i j}
\end{aligned}
$$

Where fcollege, fsenior, fjunior and below denoted father's education levels: college degree, senior high school, and junior high school and below, respectively. So did maternal education levels.

Level 2

$$
\begin{aligned}
& \beta_{0 j}=r_{00}+u_{0 j} \\
& \beta_{i j}=\gamma_{i 0}, \quad i=1, \quad 2, \cdots, 12 \\
& \beta_{13 j}(\text { Re } \text { appraisal })=r_{130} \text { or } \beta_{13 j}(\text { Suppression })=r_{130}+u_{13 j} \\
& \beta_{14 j}(\text { reappraisal } / \text { Suppression })=r_{140}+u_{14 j} \\
& \beta_{15 j}(\text { Reappraisal })=r_{150} \text { or } \beta_{15 j}(\text { Suppression })=r_{150}+u_{15 j}
\end{aligned}
$$




$$
\beta_{16 j}(\text { Reappraisal } / \text { Suppression })=r_{160}+\mu_{16 j}
$$

The intercept was allowed to vary between classroom/teachers (see equation (4)) on the level 2. The slopes for characteristics of students such as gender, grade level, father education and maternal education were fixed in two models (see equation (5)). To easily differentiate equations of reappraisal and suppression, the equation coefficients for suppression were expressed as $\beta^{\prime}{ }_{i j}, i=1,2 \cdots 16$ in the following analysis. Results were presented in Table 4.

\subsection{Reappraisal}

The slopes for EC and NA in equation (6) and (8) were fixed because their random variance components were too small $\left(\chi^{2}(53)=51.97,51.23, p>.5\right.$, respectively). EC and Affiliativeness positively predicted reappraisal ( $\beta_{13 j}$ $=.11, t(2057)=4.37, p<.01 ; \beta_{16 j}=.14, t(53)=5.23, p<.01$, respectively $)$, but NA only attained to the marginal significance $\left(\beta_{15 j}=.05, t(2057)=1.93, p<.1\right)$ whereas Surgency negatively predicted reappraisal $\left(\beta_{14 j}=-.11, t\right.$

$(53)=-4.59, p<.01)$. Other results indicated that students whose fathers accepted college education reported higher reappraisal than those whose fathers accepted over master education $\left(\beta_{7 j}=.64, t(2057)=3.16, p<.001\right)$.

Reappraisal was marginally related with grade $8\left(\beta_{2 j}=.16, t(2057)=1.78, p<.1\right)$, with eighth graders reporting higher reappraisal than seventh graders. There were no differences among maternal education levels and between genders.

\subsubsection{Suppression}

Among temperamental constructs, only NA significantly predicted suppression $\left(\beta_{15 j}^{\prime}=.09, t(2057)=3.25, p\right.$ $<.01)$. Male students reported higher suppression than did female students $\left(\beta_{1 j}^{\prime}=-.17, t(2057)=-3.69, p<.01\right)$.

Students whose father experienced senior high school had marginally lower suppression than those whose father got master degree $\left(\beta_{8 j}^{\prime}=-.41, t(2057)=-1.74, p<.1\right)$, and students whose mothers completed college displayed marginally lower suppression than those whose mothers experienced over master education $\left(\beta_{10 j}^{\prime}=-.42, t(2057)=\right.$ $-2.10, p<.1)$.

In summary, the intercepts of reappraisal and suppression became not significant after student variables entered the equations, so the following level-2 model did not analyze them and only focus on the slopes of Surgency, Affiliativeness and NA because the slope coefficients and random effects of this three temperament constructs were all significant, and doing this could also simplify the analysis process in the meantime.

\subsubsection{Teacher- level}

Descriptive statistics and correlations of teacher emotional empathy were examined (See Table 5).

The level-1 equations were the same as equation (3). The characteristics of teachers like gender and teaching experience (TE), and teacher reported emotional empathy were added to the model as level-2 predictors of intercept and several slopes at the teacher level, but no differences were observed based on teacher gender, so neglected in the following analyses. Based on student-level random effect and slope coefficients, the following level-2 models were built while other slopes were all fixed except for the level-1 intercepts.

$$
\begin{aligned}
\beta_{14 j}= & r_{140}+r_{141}\left(\text { TE } 1-5 y s_{j}\right)+r_{142}\left(\text { TE } 6-10 y s_{j}\right)+r_{143}\left(T E 11-15 y s_{j}\right)+ \\
& r_{144}\left(\text { TE } 16-20 y s_{j}\right)+r_{145}\left(\text { empathic suffering }_{j}\right)+r_{146}\left(\text { positive sharing }_{j}\right)+ \\
& r_{147}\left(\text { responsive crying }_{j}\right)+r_{148}\left(\text { emotional attention }_{j}\right)+r_{149}\left(\text { feeling for others }_{j}\right)+ \\
& r_{150}\left(\text { emotional contagion }_{j}\right)+u_{14 j} \\
\beta_{16 j}= & r_{160}+r_{161}\left(\text { empathy sum }_{j}\right)+u_{16 j}
\end{aligned}
$$

Level-2 Model of Reappraisal. As could be seen in Table 6, the Surgency slope $\beta_{14 j}$ was lower in teaching experience of 11-15 years and 16-20 years than teaching experience of over 20 years $\left(\gamma_{143}=-.11, t(43)=-2.08, p\right.$ $<.05 ; \quad \gamma_{150}=-.20, t(43)=-4.25, p<.001$, respectively). Emotional Contagion negatively predicted the Surgency slope $\beta_{14 j}\left(\gamma_{150}=-.06, t(43)=-2.39, p<.05\right)$. Although the random effect of the Affiliativeness slope $\beta_{16 j}$ had 
very significant difference at the level $2\left(\chi^{2}(52)=92.93, p<.01\right)$, the present teacher variables and characteristics of gender and teaching experience could not significantly predicted it (The characteristics of gender and teaching experience were left out in equation (11) for model conciseness).

Level-2 model of Suppression. Results from the equation $\beta_{15 j}{ }_{15}$ were displayed in Table 7. Compared with teaching experience of over 20 years, the NA slope was lower in teaching experience of 1-5 years and 16-20 years (marginally significant, $\gamma_{151}^{\prime}=-.10, t(43)=-2.00, p<.1 ; \quad \gamma_{154}^{\prime}=-.20, t(43)=-2.72, p<.01$, respectively)

whereas higher in teaching age 6-10 years and 11-15 years (marginally significant, $\gamma_{152}^{\prime}=.13, t(43)=1.81, p<.1$; $\gamma_{153}^{\prime}=.11, t(43)=1.96, p<.1$, respectively). Moreover, the slope of NA was positively correlated with teacher reported Responsive Crying $\left(\gamma_{157}^{\prime}=.05, t(43)=2.49, p<.05\right)$, Emotional Attention $\left(\gamma_{158}^{\prime}=.09, t(43)=3.52, p\right.$ $<.01)$ and Feeling for Others $\left(\gamma_{159}^{\prime}=.11, t(43)=3.43, p<.01\right)$. However, Positive Sharing negatively predicted the rate of change in NA $\left(\gamma_{156}^{\prime}=-.07, t(43)=-2.20, p<.05\right)$.

\section{Discussion}

The present study aimed to examine influential factors of adolescent ER at the student-level and the teacher-level using HLM. Results indicated that several demographic characteristics were significantly correlated with reappraisal and suppression at the student level. Consistent with other studies based on Chinese context (Wang et al., 2009), male adolescents used the suppressive regulation strategy more often than female, but no significant gender differences were found in reappraisal. It is surprising that adolescents whose fathers have received college education reported higher reappraisal than those whose fathers have master degree, but it is unclear why only fathers' education played more roles in reappraisal style of adolescents. These background variables related to ER seemed to reflect the social environmental impacts on the development of adolescents' different ER strategies (Raikes \& Thompson, 2006).

At the student level, this study provided direct evidence for the relationship between temperament and ER strategies of reappraisal and suppression, especially EC. Results indicated that EC positively predicted reappraisal, but could not predict suppression. In addition, the random effect of EC slope was not significant. Thus, consistent with other researches, EC is mainly an outcome of the development of executive control of attention (Rothbart \& Rueda, 2005; Rothbart, 2007; Spinrad et al., 2007). During adolescence young students gain higher level cognitive ability with brain maturation so as to improve their ability to regulate emotions, including more flexible reappraisal strategy, which has important implications for their social competence and adjustment. For example, adolescents of low EC suffered the disruption of normal developmental process and were placed particularly higher risk for psychological disorder (Muris \& Ollendick, 2005).

At the teacher level, there were no significant difference in the mean level of classroom in the ER strategies of reappraisal and suppression, but the role of head teachers should not be neglected. Compared with teaching experience of over 20 years, teaching experience of 16-20 years was correlated negatively with the rate of change in Surgency and NA. One possible explanations is that during the period head teachers are suffering job burnout (Song, 2008), and it is a crucial period when head teacher are under a lot of stresses, experiencing more negative emotions and tired of teaching and classroom management (Carmona et al., 2006).

This study provided meaningful information about the modulation of teacher emotional empathy on the association between temperament and ER using HLM. Results showed that the lever of teachers' Emotional Contagion strengthened the influence of adolescent Surgency upon reappraisal. As a higher-level temperament factor, Surgency, which is also called Extraversion (Putnam \& Stifter, 2008), includes high intensity of pleasure, low-level of fear and low-level of shyness. From the student level, it is easily known that Surgency negatively predicted reappraisal after the demographic variables are controlled, which is not consistent with the findings by Gross and John (2003) that there was no significant correlation between extraversion and ERQ reappraisal. Maybe in the classroom, head teachers with high emotional contagion urge students who have high Surgency to release negative emotions in time by physical activities or facial expressions so that they use reappraisal strategy less.

Another unique piece of information provided by this study is that teacher emotional empathy modulated the influence of NA on Suppression. From the teach-level, we know that teacher reported Responsive Crying, Emotional Attention and Feeling for Others enhanced the effect of NA on Suppression. However, Positive Sharing reduced the negative correlation between NA and Suppression. NA is susceptible to negative emotions, which is consistent with the dimension of Neuroticism (Ellenbogen \& Hodgins, 2004), and associated with internalizing problems (Rettew \& McKee, 2005). It seems that students with high NA get used to suppression strategy as indicated by the student level analysis. When head teachers display empathy for them such as Responsive Crying, Emotional Attention and Feeling for Others through verbal and nonverbal messages, which activate them to pay 
more attention to their own negative emotions, they automatically suppress their own negative emotions instead of stopping use more adaptable regulation methods. Obviously, this further may reinforce their suppression behaviors, which seems partly to explicate why NA is associated positively with Suppression. However, when head teachers display Positive Sharing with students with high NA, they aware teachers' genuine concern and feel being respectable (Brown, 2005), thus they do not suppress negative emotions anymore, but choose more cooperative fashions to regulate emotions. Of course, the nature of correlative data in the present research can not be allowed to make such a cause-effect inference, but this prompt us to make further field research by intervention or observation in the future to verify the process.

The present study extends the knowledge about the function of teacher empathy in adolescents' development of emotion. Classroom management and teacher training can use the results of the current study in preparing teachers to be aware of their specific roles in adolescent's ER. Empathy is the most consistently mentioned as one of major elements of good teaching (Dewar, 2002; Tettegah \& Anderson, 2007), but is also seen as a varied and complex phenomenon which shows itself to different degrees and extents in different contexts (Cooper, 2004). Different aspects of teacher emotional empathy exert different modulations to the impact of temperament on ER, which remind us of noticing the effect of routine empathy training of teacher. That is, it is only a necessary condition that a teacher has high empathy. If the characteristics of teacher emotional empathy do not match with students' temperamental features, their ER processes will be intervened and harmed. To improve adolescents' ER ability, teachers should first learn how to assess students' temperament and be aware of their temperamental characteristics (Rothbart \& Jones, 1998) and ER styles (Leung \& Lam, 2003). Then teachers should display different aspects of their emotional empathy in classroom management or one-to-one interview based on students' different temperament through verbal and nonverbal messages. For example, when teachers show positive sharing with emotions of high NA students, they could use suppression strategy less, which might activate them to become more open and learn to reappraise emotional events under teachers' modeling (Nickerson et al., 2008). Hence they could gain positive emotional experience and display more prosocial behaviors (Kidron \& Fleischman, 2006).

The limitations of the present study need to be mentioned here. First, all the predictors were based on self-report. Variance components in the unconditional models were also small, which weakened the explanatory ability of teacher variables at the level-2. Second, reappraisal was significantly correlated with suppression, which is inconsistent with the finding by Gross and John (2003) that there was non-significant correlated between them. One possible explanation is that Chinese students may alternate the employment of these two regulatory strategies on different occasions as they might be both adaptable in Chinese cultural context. Finally, Affiliativeness had significant difference at the teacher level, but when teacher emotional empathy was entered into the equation on the level 2, the random effect still kept significant, which prompts that other classroom variables may be at work, or there are level-3 (between-school) differences which are not studied because only four schools are not enough to research level-3 model in this study. Future studies may involve more teacher variables such as teachers' emotional intelligence (Kremenitzer, 2009) and classroom affective management, or extend to more schools in order to differentiate between-school variation.

\section{References}

Blair, K.A., Denham, S.A., Kochanoff, A., \& Whipple, B. (2004). Playing it cool: Temperament, emotion regulation, and social behavior in preschoolers. Journal of School Psychology, 42, 419-443.

Brown, D. F. (2005). The significance of congruent communication in effective classroom management. The Clearing House, 79(1), 12-15.

Campos, J.J., Frankel, C.B., \& Camras, L. (2004). On the nature of emotion regulation. Child Development, 75 , 377-394.

Capaldi, D. M., \& Rothbart, M.K. (1992). Development and validation of an early adolescent temperament measure. Journal of Early Adolescence, 12(2), 153-173.

Carmona, C., Buunk, P.A, \& Peiro, M.J. et al. (2006). Do social comparison and coping styles play a role in the development of burnout? Cross-sectional and longitudinal findings. Journal of Occupational Organizational Psychology, 79, 85-99.

Caruso, D. R., \& Mayer, J. D. (1998). A measure of emotional empathy for adolescents and adults. Unpublished Manuscript.

Cooper, B. (2004). Empathy, interaction and caring: Teachers' roles in a constrained environment. Pastoral Care in Education, 22(3), 12 - 21.

Cumberland-Li, A., Eisenberg, N., \& Champion, C., et al. (2003). The relation of parental emotionality and related 
dispositional traits to parental expression of emotion and children's social functioning. Motivation \& Emotion. Special Issue: Developmental aspects of emotion regulation across the lifespan: Integrating diverse developmental perspectives, Part I 27(1), 27-56.

Davis, M.H. (1983). Measuring individual differences in empathy: Evidence for a multidimensional approach. Journal of Personality and Social Psychology, 44, 113-126.

Dewar, K. (2002). On being a good teacher. Journal of Hospitality, Leisure, Sport and Tourism Education, 1(1), 61-67.

Eisenberg, N., Ma, Y., \& Chang, L. et al. (2007). Relations of effortful control, reactive undercontrol, and anger to Chinese children's adjustment. Development and Psychopathology, 19, 385-409.

Ellenbogen, M. A., \& Hodgins, S. (2004). The impact of high neuroticism in patients on children's psychosocial functioning in a population at high risk for major affective disorder: A family-environmental pathway of intergenerational risk. Development and Psychopathology, 16(1), 113-136.

Ellis, L. K., \& Rothbart, M. K. (April, 2001). Revision of the early adolescent temperament questionnaire. Poster presented at the biennial meeting of the Society for Research in Child Development, Minneapolis, MN.

Good, T. L., \& Brophy, J. E. (2000). Motivation. In T. Good \& J. Brophy (Eds.), Looking in classrooms (pp. 217-267). New York, NY: Longman

Gross, J. J. (1998). The emerging field of emotion regulation: an integrative review. Review of General Psychology, 2, 271-299.

Gross, J. J., \& John, O. P. (2003). Individual differences in two emotion regulation processes: Implications for affect, relationships, and well-being. Journal of Personality \& Social Psychology, 85(2), 348-362.

Gross, J.J., \& Thompson, R.A. (2007). Emotion regulation: Conceptual foundations. In Gross, J.J. (Ed). Handbook of Emotion Regulation (pp. 3-24). New York: Guilford.

Kidron, Y., \& Fleischman, S. (April, 2006). Promoting adolescents' prosocial behavior. Educational leadership, 90-91.

Kremenitzer, J. (2009). Emotional intelligence ability and the teacher candidate. Paper presented at the annual meeting of the American Association of Colleges for Teacher Education Online $<\mathrm{PDF}>$. [Online] Available: http://www.allacademic.com/meta/p35510_index.html (February 5, 2009)

Leung, C.M., \& Lam, S.F. (2003). The effects of regulatory focus on teachers' classroom management strategies and emotional consequences. Contemporary Educational Psychology, 28(1), 114-125.

McWayne, C., Campos, R., \& Owsianik, M. (2008). A multidimensional, multilevel examination of mother and father involvement among culturally diverse Head Start families. Journal of School Psychology, 46, 551-573.

Muris, P., \& Ollendick, T. H. (2005). The role of temperament in the etiology of child psychopathology. Clinical Child \& Family Psychology Review, 8(4), 271-289.

Murray, C., \& Malmgren, K. (2005). Implementing a teacher-student relationship program in a high-poverty urban school: Effects on social, emotional, and academic adjustment and lessons learned. Journal of School Psychology, 43, 137-152

Nickerson, A.B., Mele, D., \& Princiott, D. (2008). Attachment and empathy as predictors of roles as defenders or outsiders in bullying interactions. Journal of School Psychology, 46(6), 687-703.

Putnam, S.P., \& Stifter, C.A. (2008). Reactivity and regulation: the impact of Mary Rothbart on the study of temperament. Infant and Child Development, 17, 311-320.

Raikes, H.A., \& Thompson, R.A. (2006). Family emotional climate, attachment security, and young children's emotion understanding in a high-risk sample. British Journal of Developmental Psychology, 24, 989-1104.

Raudenbush, S.W., \& Bryk, A.S. (2002). Hierarchical Linear Models: Applications and Data Analysis Methods, Second Edition. Newbury Park, CA: Sage.

Rettew, D.C., \& McKee, L. (2005). Temperament and its role in developmental psychopathology. Harvard Review of Psychiatry, 13(1), 14-27.

Rothbart, M. K., \& Rueda, M. R. (2005). The development of effortful control. In U. Mayr, E. Awh, \& S. Keele (Eds.), Developing individuality in the human brain: A tribute to Michael I. Posner (pp. 167-188). Washington, D.C.: American Psychological Association. 
Rothbart, M.K. (2007). Temperament, development, and personality. Current directions in psychological science, 16(4), 207-211.

Rothbart, M.K., \& Bates, J.E. (2006). Temperament, In W. Damon (Series Ed.) \& N. Eisenberg (Vol. Ed.), Handbook of child psychology: Vol3. Social, emotional, and personality development ( ${ }^{\text {th }}$ ed., pp.99-166). New York: Wiley.

Rothbart, M.K., \& Jones, L.B. (1998). Temperament, self-regulation and education. School Psychology Review, 27(4), 479-491

Song, Z.Y. (2008). Current situation of job burnout of junior high school teachers in Shangqiu urban areas and its relationship with social support. Frontiers of Education in China, 3(2), 295-309.

Spinrad, T.L., Eidenberg, N., \& Gaertner, B.M. (2007). Measures of effortful regulation for younger children. Infant mental health Journal, 28(6), 606-626.

Tettegah, S., \& Anderson, C.J. (2007). Pre-service teachers' empathy and cognitions: Statistical analysis of text data by graphical models. Contemporary educational psychology, 32(1), 48-82.

Thornton, S., \& Thornton, D. (1995). Facets of empathy. Personality and Individual Differences, 19, 765-767.

Wang, L., Shi, Z.B., \& Li, H.H. (2009). Neuroticism, extraversion, emotion regulation, NA and positive affect: The mediating roles of reappraisal and suppression. Social Behavior and Personality, 37(2), 193-194.

Yap, M.B.H., Allen, N. B., \& Sheeber, L. (2007). Using an emotion regulation framework to understand the role of temperament and family processes in risk for adolescent depressive disorders. Clinical Child and Family Psychology, 10(2), 180-196.

Zeman, J., Cassano, M., Perry-Parrish, C., \& Stegall, S. (2006). Emotion regulation in children and adolescents. Journal of Developmental \& Behavioral Pediatrics, 27, 155-168. 
Table 1. The student number distribution of gender and among schools, grade levels

\begin{tabular}{llllllll}
\hline & Grade 7 & & Grade 8 & & Grade 9 & Total \\
\cline { 2 - 7 } & M & F & M & F & M & F & \\
\hline Junior high school 1 & 51 & 61 & 74 & 46 & 71 & 47 & 350 \\
Junior high school 2 & 96 & 129 & 102 & 109 & 107 & 125 & 668 \\
Total & 147 & 190 & 176 & 155 & 178 & 173 & 1018 \\
\hline \multirow{2}{*}{ Grade 10 } & & Grade 11 & & Grade 12 & \\
\cline { 2 - 6 } & M & F & M & F & M & F & \\
\hline Senior high school 1 & 105 & 97 & 141 & 152 & 127 & 88 & 710 \\
Senior high school 2 & 66 & 48 & 67 & 62 & 52 & 51 & 346 \\
Total & 171 & 145 & 208 & 214 & 179 & 139 & 1056 \\
\hline
\end{tabular}

$\mathrm{N}=2074 . \mathrm{M}=$ male. $\mathrm{F}=$ female.

Table 2. Descriptive statistics and correlations among student-level variables

\begin{tabular}{|c|c|c|c|c|c|c|c|c|}
\hline Variable & $M$ & $S D$ & Range & 1 & 2 & 3 & 4 & 5 \\
\hline 1. EC & 3.33 & .44 & $1.88-5.00$ & & & & & \\
\hline 2. Surgency & 2.38 & .43 & $.81-4.13$ & $.14 *$ & & & & \\
\hline 3. NA & 2.88 & .48 & $1.11-5.00$ & $-.38 * *$ & $-.31 * *$ & & & \\
\hline 4. Affiliativeness & 3.63 & .54 & $1.71-5.00$ & $.28 * *$ & $-.09 * *$ & $.13^{* *}$ & & \\
\hline 5. Reappraisal & 25.43 & 5.78 & $6.00-42.00$ & $.14 * *$ & $-.12 * *$ & $.05 *$ & $.19^{* *}$ & \\
\hline 6. Suppression & 16.11 & 4.68 & $4.00-28.00$ & -.01 & -.02 & $.10^{* *}$ & $.05^{*}$ & $.18 * *$ \\
\hline
\end{tabular}

$\mathrm{N}=2074 . \mathrm{EC}=$ Effortful Control; NA = Negative Affect.

${ }^{*} p<.05 ; * * p<.01$.

Table 3. Variance components and reliability of unconditional model

\begin{tabular}{llllll}
\hline & VC & $\chi^{2}$ & $p$ & $d f$ & Reliability \\
\hline Reappraisal & .06 & 115.70 & $.00^{* * *}$ & 53 & .74 \\
Suppression & .07 & 142.19 & $.00^{* * *}$ & 53 & .78 \\
\hline
\end{tabular}

$\mathrm{N}=2074$. VC=variance component.

$* * * p<.001$. 
Table 4. Student-level analysis of Reappraisal and Suppression

\begin{tabular}{|c|c|c|c|c|c|c|}
\hline \multirow[b]{2}{*}{ Fixed Effect } & \multicolumn{2}{|c|}{ Reappraisal } & \multicolumn{4}{|c|}{ Suppression } \\
\hline & coefficient & t-ratio & $p$ & coefficient & t-ratio & $p$ \\
\hline Intercept & $.01(.05)$ & $.16^{\mathrm{a}}$ & .87 & $.08(.08)$ & 1.00 & .29 \\
\hline Gender & $-.05(.04)$ & -.05 & .29 & $-.17(.04)$ & -3.69 & $.00 * * *$ \\
\hline Grade 8 & $.16(.09)$ & 1.78 & .07 & $-.14(.12)$ & -1.22 & .24 \\
\hline Grade 9 & $.07(.10)$ & .71 & .47 & $-.08(.09)$ & -.72 & .33 \\
\hline Grade 10 & $-.02(.07)$ & -.28 & .77 & $-.09(.12)$ & -.77 & .43 \\
\hline Grade 11 & $-.13(008)$ & -1.64 & .10 & $-.09(.11)$ & -.80 & .40 \\
\hline Grade 12 & $.11(.07)$ & -1.56 & .11 & $-.09(.10)$ & -.78 & .37 \\
\hline \multicolumn{7}{|l|}{ Father education } \\
\hline College & $.64(.20)$ & 3.16 & $.00 * * *$ & -.25 & -1.03 & .31 \\
\hline Senior school & $.00(.11)$ & .06 & .94 & -.41 & -1.74 & .07 \\
\hline Junior and below & $.02(.05)$ & .38 & .70 & -.38 & -1.60 & .12 \\
\hline \multicolumn{7}{|l|}{ Maternal education } \\
\hline College & $-.09(.11)$ & -.82 & .41 & $-.42(.23)$ & -2.10 & .06 \\
\hline Senior school & $-.15(.13)$ & -1.16 & .24 & $.06(.24)$ & .37 & .78 \\
\hline Junior and below & $-.02(.07)$ & -.39 & .69 & $-.11(.25)$ & -.67 & .64 \\
\hline $\mathrm{EC}$ & $.11(.02)$ & 4.37 & $.00 * * *$ & $.01(.02)$ & .59 & .54 \\
\hline Surgency & $-.11(.02)$ & $-4.59^{\mathrm{a}}$ & $.00 * * *$ & $-.00(.01)$ & -.13 & .87 \\
\hline NA & $.05(.02)$ & 1.93 & .05 & $.09(.02)$ & 3.25 & $.00 * *$ \\
\hline Affiliativeness & $.14(.02)$ & $5.23^{\mathrm{a}}$ & $.00 * * *$ & $.02(.02)$ & 1.09 & .24 \\
\hline Random Effect & $\mathrm{VC}$ & $\chi^{2}$ & $p$ & $\mathrm{VC}$ & $\chi^{2}$ & $p$ \\
\hline Intercept 1 & $.03(.16)$ & 103.27 & $.00 * * *$ & $.04(.21)$ & 147.54 & $.00 * * *$ \\
\hline EC slope & & & & $.02(.12)$ & 74.93 & $.02 *$ \\
\hline Surgency slope & $.01(.10)$ & 76.89 & $.01 *$ & $.00(.04)$ & 35.56 & $>.05$ \\
\hline NA slope & & & & $.01(.11)$ & 72.82 & $.03 *$ \\
\hline Affiliativeness slope & $.02(.14)$ & 93.80 & $.00 * *$ & $.00(.05)$ & 43.41 & $>.05$ \\
\hline
\end{tabular}

Standard errors are in parentheses. ${ }^{\text {a }}$ denotes $53 \mathrm{dfs}$ while other dfs are $2057 . \mathrm{VC}=$ variance component; $\mathrm{EC}=$ Effortful Control; NA = Negative Affect.

${ }^{*} p<.05 .{ }^{* *} p<.01 . * * * p<.001$. 
Table 5. Descriptive statistics and correlations among different factors of teacher empathy

\begin{tabular}{lllllllll}
\hline Variable & $M$ & $S D$ & Range & 1 & 2 & 3 & 4 & 5 \\
\hline 1. Empathic Suffering & 31.70 & 4.44 & $20-40$ & & & & & \\
2. Positive Sharing & 20.29 & 2.85 & $11-25$ & $.72^{* *}$ & & & & \\
3. Responsive Crying & 9.26 & 2.07 & $5-14$ & .09 & .17 & & & \\
4. Emotional Attention & 12.04 & 3.22 & $5-18$ & .05 & .12 & $-.44^{* *}$ & & \\
5. Feeling for Others & 15.04 & 2.71 & $10-20$ & $.63^{* *}$ & $.51^{* *}$ & .08 & -.23 & \\
6.Emotional Contagion & 7.46 & 1.74 & $2-10$ & $.35^{* *}$ & $.55^{* *}$ & .02 & -.19 & $.39^{* *}$
\end{tabular}

$\mathrm{N}=54$.

$*_{p}<.05 ; * * p<.01$.

Table 6. Teacher-level analysis for the slopes of Surgency and Affiliativeness

\begin{tabular}{|c|c|c|c|c|}
\hline Fixed Effect & coefficient & t-ratio & $d f$ & $p$ \\
\hline \multicolumn{5}{|c|}{ Model for Surgency slope, $\beta_{14}$} \\
\hline Intercept 2 & $-.11(.02)$ & -5.63 & 43 & $.00 * * *$ \\
\hline TE: $1-5$ years & $-.01(.06)$ & -.23 & 43 & .81 \\
\hline $6-10$ years & $-.01(.05)$ & -2.08 & 43 & .75 \\
\hline $11-15$ years & $-.11(.05)$ & -.31 & 43 & $.04 *$ \\
\hline $16-20$ years & $-.20(.04)$ & -4.25 & 43 & $.00^{* * *}$ \\
\hline Empathic Suffering & $.00(.03)$ & .08 & 43 & .94 \\
\hline Positive Sharing & $.04(.03)$ & 1.22 & 43 & .22 \\
\hline Responsive Crying & $.02(.03)$ & .88 & 43 & .38 \\
\hline Emotional Attention & $-.01(.02)$ & -.47 & 43 & .64 \\
\hline Feeling for Others & $.02(.03)$ & .84 & 43 & .40 \\
\hline Emotional Contagion & $-.06(.02)$ & -2.39 & 43 & $.02 *$ \\
\hline \multicolumn{5}{|c|}{ Model for Affiliativeness slope, $\beta_{16}$} \\
\hline Intercept 2 & $.14(.02)$ & 5.34 & 52 & $.00 * * *$ \\
\hline Empathy sum & $-.03(.03)$ & -.95 & 52 & .34 \\
\hline Random Effect & $\mathrm{VC}$ & $\chi^{2}$ & $d f$ & $p$ \\
\hline Intercept1 & $.02(.16)$ & $102.35 * * *$ & 53 & $.00 * * *$ \\
\hline Surgency slope & $.00(.06)$ & 51.23 & 43 & .18 \\
\hline Affiliativeness slope & $.02(.13)$ & $92.93 * *$ & 52 & $.00 * *$ \\
\hline level-1 & .88 & & & \\
\hline
\end{tabular}

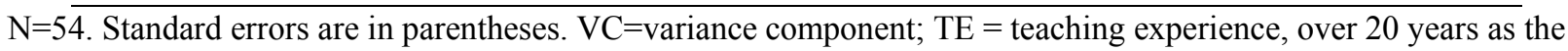
comparison group.

$* p<.05 ; * * p<.01 ; * * * p<.001$. 
Table 7. Teacher-level analysis for the slope of NA

\begin{tabular}{|c|c|c|c|c|}
\hline Fixed Effect & coefficient & t-ratio & $d f$ & $p$ \\
\hline \multicolumn{5}{|c|}{ Model for NA slope, $\beta_{15 j}^{\prime}$} \\
\hline Intercept 2 & $.10(.02)$ & 4.14 & 43 & $.00 * * *$ \\
\hline TE: $1-5$ yeas & $-.10(.05)$ & -2.00 & 43 & .05 \\
\hline $6-10$ years & $.13(.07)$ & 1.81 & 43 & .07 \\
\hline $11-15$ years & $.11(.06)$ & 1.96 & 43 & .05 \\
\hline $16-20$ years & $-.20(.07)$ & -2.72 & 43 & $.01 *$ \\
\hline Empathic Suffering & $.02(.03)$ & .94 & 43 & .35 \\
\hline Positive Sharing & $-.07(.03)$ & -2.20 & 43 & $.03 *$ \\
\hline Responsive Crying & $.05(.02)$ & 2.49 & 43 & $.01 *$ \\
\hline Emotional Attention & $.09(.02)$ & 3.52 & 43 & $.00 * *$ \\
\hline Feeling for Others & $.11(.03)$ & 3.43 & 43 & $.00 * *$ \\
\hline Emotional Contagion & $-.01(.02)$ & -.67 & 43 & .50 \\
\hline Random Effect & $\mathrm{VC}$ & $\chi^{2}$ & $d f$ & $p$ \\
\hline Intercept1 & .04 & $142.22 * * *$ & 53 & .00 \\
\hline NA slope & .00 & 49.09 & 43 & .24 \\
\hline level-1 & .90 & & & \\
\hline
\end{tabular}

$\mathrm{N}=54 . \mathrm{VC}=$ variance component; $\mathrm{NA}=$ Negative Affect; $\mathrm{TE}=$ teaching experience, over 20 years as the comparison group.

$* p<.05 ; * * p<.01 ; * * * p<.001$. 